\title{
Effect of Compound-Maqin-Decoction on P38MAPK and Foxp3 Protein Expression of Lung Issue in Asthmatic Rats
}

\author{
Peng QIAN \\ College of Basic Medicine \\ Shanghai University of Traditional Chinese Medicine \\ Shanghai, China \\ e-mail: qqpp2000439@163.com
}

Xueping LI

College of Basic Medicine

Shanghai University of Traditional Chinese Medicine

Shanghai, China

e-mail: 1403759578@qq.com

\author{
Zhaoxia XU* \\ College of Basic Medicine \\ Shanghai University of Traditional Chinese Medicine \\ Shanghai, China \\ e-mail: zhaoxia7001@126.com
}

Sijing WANG

College of Basic Medicine

Shanghai University of Traditional Chinese Medicine Shanghai, China

e-mail: 1158278555@qq.com

\begin{abstract}
OBJECTIVE: To observe the effect of CompoundMaqin-Decoction (CMD) on p38MAPK and Foxp3protein expression of lung issue in asthmatic rats. METHODS: The asthmatic rat model was established by ovalbumin and was intervened with CMD. After inducing asthma and four-week treatment, the rats were sacrificed to immunohistochemicallly detect P38MAPK and Foxp3 protein expressions in lung tissue. RESULTS: After treatment, compared with model group, P38MAPK protein expression decreased and Foxp3 was increased in dexamethasone, large doses CMD and small doses CMD groups, there were statistically significant differences between dexamethasone group and large doses CMD group. Compared with dexamethasone group, P38MAPK protein expression decreased and Foxp3 was increased in large doses CMD and small doses CMD groups, there were statistically significant differences between dexamethasone group and large doses CMD group. Conclusion: CMD is effective in asthmatic airway remodeling, which may be due to its regulatory effect on the expressions of p38MAPK and Foxp3 protein.
\end{abstract}

Keywords-asthma; Р38MAPK; Foxp3; Compound-MaqinDecoction

\section{INTRODUCTION}

Pathogenesis of asthma is complex, many factors involved. Many studies show that asthma is a chronic allergic airway inflammation, and airway remodeling is regarded as important inflammatory mediators that caused irreversible airway obstruction and airway hyper responsiveness. Regular $\mathrm{T}$ cells(Treg) are regarded as immunosuppressive $\mathrm{T}$ lymphocytes, involving in maintaining immune balance, inducing immune tolerance, against infection, anti-tumor immune responses, and so on [1]. Fork head transcription facter3 (Foxp3) is currently accepted most sensitive marker of Treg cells. P38 mitogen-activated protein kinase(p38 MAPK) is an important intracellular signal transduction, that participate in a variety of inflammatory cytokines and various types of cellular stress signal transduction. P38MAPK plays an important role in the occurrence and development of asthma [2]. Compound-Maqin-Decoction (CMD) can regulate immune function, inhibit inflammation, relax bronchial smooth muscle, control airway inflammation, and improve lung function in asthmatic guinea pigs. These findings have been confirmed by clinical and experimental studies in the past 20 years [3-5] In the current study, we observed effect of CMD on p38MAPK and Foxp3 protein expression of lung issue in asthma rats, to investigate the asthma pathogenesis and the effector mechanisms of CMD.

\section{MATERIAL AND METHODS}

Wherever Times is specified, Times Roman or Times New Roman may be used. If neither is available on your word processor, please use the font closest in appearance to Times. Avoid using bit-mapped fonts if possible. True-Type 1 or Open Type fonts are preferred. Please embed symbol fonts, as well, for math, etc.

\section{EASE OF USE}

\section{A. Animal Grouping}

Fifty healthy SD male rats (Shanghai SLAC Laboratory Animal Co., Ltd, Shanghai, China), weighing 200 \pm 20 g, were randomly divided into five groups, as follows: normal control group (Group A); model group (Group B); dexamethasone group (Group $\mathrm{C}$ ); large doses CMD group (Group D) and small doses CMD group (Group E), 10 each.

\section{B. Modeling Method}

The asthma rat model was prepared by injecting ovalbumin (OVA) into the abdominal cavity and inhalation of aerosol based on the modeling method previously described [6]. On the first day after animal grouping, each rat in groups $\mathrm{B}, \mathrm{C}$, and $\mathrm{D}$ was injected in traperitoneally with $1 \mathrm{ml}$ of solution containing $100 \mathrm{mg}$ of OVA and 100 
mg of aluminum hydroxide. After 14 days, an aerosol inhalation of 1\% OVA was administered for 20 min ata flow rate of $2 \mathrm{ml} \cdot \mathrm{min}^{-1}$, and continued for 28 days. The rats in group A were injected with $1 \mathrm{ml}$ of $0.9 \%$ sodium chloride solution and an aerosol inhalation of $0.9 \%$ sodium chloride solution was administered a flow rate of $2 \mathrm{ml} \cdot \mathrm{min}^{-1}$, and continued for 28 days.

\section{Treatment Intervention}

Dexamethasone tablets (No. H3120793-01; Shanghai Xinyi Pharmaceutical Factory Co., Ltd., Shanghai, China) were prepared as a suspension $\left(0.32 \mathrm{mg} \cdot \mathrm{mL}^{-1}\right)$ with $0.9 \%$ sodium chloride solution.CMD consists of Zhimahuang(Ephedra; 4 grams), Huangqin (Scutelleria; 9grams), Cangerzi (Xanthium; 9grams), Tianzhuzi (Nandina domestica; 9 grams), Lameihua (Chimonanthus praecox flowers; 9grams), and Hutuiziye (Elaeagnus leaf; 9 grams). These herbs of the prescriptions were soaked in water for $1 \mathrm{~h}$. Ten volumes of water were added during the first time cooking. Four volumes of water were added during the second time cooking. Then, the prepared decoctions from both cooking times were collected, evaporated, and concentrated into a $3 g \cdot \mathrm{mL}^{-1}$ crude drug solution.

The first day after asthma was induced, rats in group A and $\mathrm{B}$ were given normal saline by gavage, rats in group $\mathrm{C}$ were given dexamethasone by gavage, rats in group $\mathrm{D}$ and $\mathrm{E}$ were respectively given large and small doses CMD decoction by gavage $\left(10 \mathrm{ml} \cdot \mathrm{kg}^{-1}\right.$ body weight once daily). After 4 weeks, materials were collected for the detection of relevant indicators.

\section{Detection Method and Indicators}

All rats were sacrificed at the end day of rats modeling, thoracotomy, exposed lung, take the right lung tissues to immerse in $4 \%$ paraformaldehyde solution, fixed for 24 hours, then cut the lung tissue into thick slices $3 \mathrm{~mm}$ each. Then continue to fix for 72 hours with $4 \%$ paraformaldehyde, graded ethanol with dehydration, clear with xylene, paraffin embedded directional, serial sections, thick $6 \mu \mathrm{m}$ each to detect by immunohistochemical method.

Take lung tissue sections to detect using immunohistochemistry according to kit instructions.

After immunohistochemical staining, lung tissue sections of rats were seen brown-yellow immunoreactivity positive reaction, positive expression mainly in the airway epithelium, submucosal, smooth muscle layer. We measured gray value with image analysis system (Olympus IX51), taking the positive rate of area percentage of the total area for comparison.

\section{E. Statistically Analysis}

All the experimental data were analyzed statistically by SPSS18.0 statistical software. ANOVA was used for the analysis, but variance nonhomogeneity, then using rank sum test, And the $\mathrm{P}<0.05$ was considered as statistically significant difference.

\section{F. Selecting A Template}

First, confirm that you have the correct template for your paper size. This template has been tailored for output on the
US-letter paper size. If you are using A4-sized paper, please close this template and download the file for A4 paper format.

\section{G. Maintaining The Integrity of The Specifications}

The template is used to format your paper and style the text. All margins, column widths, line spaces, and text fonts are prescribed; please do not alter them. You may note peculiarities. For example, the head margin in this template measures proportionately more than is customary. This measurement and others are deliberate, using specifications that anticipate your paper as one part of the entire proceedings, and not as an independent document. Please do not revise any of the current designations.

\section{RESUlts}

\section{A. General Observation}

The rats in groups A are good, lively and good move, supple fur, weight gradually increased, breathing smoothly and evenly. The rats in group B are worse than group A, apathetic, slow, gloss hair down, after induced asthma, the rats in group B are irritability, shortness of breath, sneezing or cough, mild cyanosis, muscle twitching, unresponsive and other symptoms. After the treatment by Dexamethasone and CMD, above asthma symptoms relieve, and the symptoms of large dose CMD group is better than two treatment groups.

\section{B. P38MAPK and Foxp3 Protein Expression of Lung Issue in Asthmatic Rats}

Because the data of group A-E is not homogeneous, we used the rank sum test to compare the difference between groups. Compared with group A, P38MAPK protein expression decreased and Foxp3 was increased in other groups, there were statistically significant differences between group $\mathrm{A}$ and $\mathrm{B}$. Compared with group B,P38MAPK protein expression decreased and Foxp3 was increased in group $\mathrm{C}, \mathrm{D}$ and $\mathrm{E}$, there were statistically significant differences between group C and D. Compared with group C, P38MAPK protein expression decreased and Foxp3 was increased in group $\mathrm{D}$ and $\mathrm{E}$, there were statistically significant differences between group C and D. The results are shown in figur1 and table I and II. 
TABLE I. FoXP3 ProteIn OF LUNG IsSUE IN AsthMATIC RATS(RANK SUM TEST)

\begin{tabular}{lccc}
\hline & $\begin{array}{c}\text { Mann-Whitney } \\
\text { U }\end{array}$ & $\mathrm{Z}$ & $\begin{array}{c}\text { Significant } \\
\text { (both sides) }\end{array}$ \\
\hline Group A and B & 12 & -2.1 & $0.036^{*}$ \\
Group A and C & 5 & -2.836 & $0.005^{* *}$ \\
Group A and D & 29 & -0.315 & 0.753 \\
Group A and E & 27 & -0.525 & 0.6 \\
Group B and C & 26 & -0.63 & 0.529 \\
Group B and D & 12 & -2.1 & $0.036^{*}$ \\
Group B and E & 16 & -1.68 & 0.093 \\
Group C and D & 0 & -3.361 & $0.001^{* *}$ \\
Group C and E & 2 & -3.151 & $0.002^{* *}$ \\
Group D and E & 16 & -1.683 & 0.092 \\
\hline & & & NOTE: * $<0.05 . * * \mathrm{p}<0.01$
\end{tabular}

TABLE II. P38MAPK PRoteIn OF LUNG Issue IN AsthMATIC RATS(RANK SUM TEST)

\begin{tabular}{lccc}
\hline & $\begin{array}{c}\text { Mann- } \\
\text { Whitney U }\end{array}$ & Z & $\begin{array}{c}\text { Significant } \\
\text { (both sides) }\end{array}$ \\
\hline Group A and B & 10 & -2.31 & $0.021^{*}$ \\
Group A and C & 24 & -0.84 & 0.401 \\
Group A and D & 25 & -0.735 & 0.462 \\
Group A and E & 19 & -1.365 & 0.172 \\
Group B and C & 9 & -2.415 & $0.016^{*}$ \\
Group B and D & 13 & -1.995 & $0.046^{*}$ \\
Group B and E & 21 & -1.155 & 0.248 \\
Group C and D & 28 & -0.42 & 0.674 \\
Group C and E & 27 & -0.525 & 0.6 \\
Group D and E & 27 & -0.525 & 0.6 \\
\hline
\end{tabular}

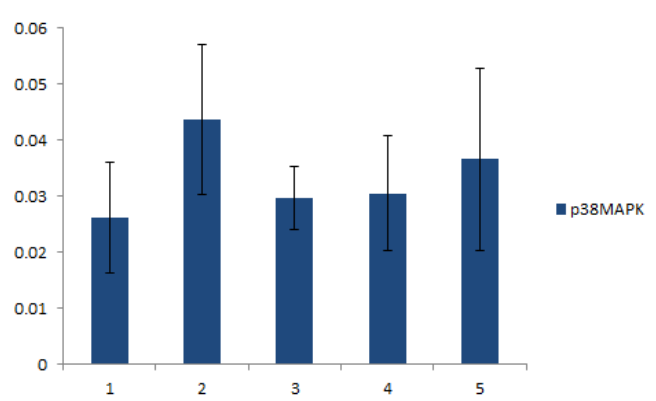

Figure 1. The mean of p38mapk protein expression of lung issue in asthmatic rats

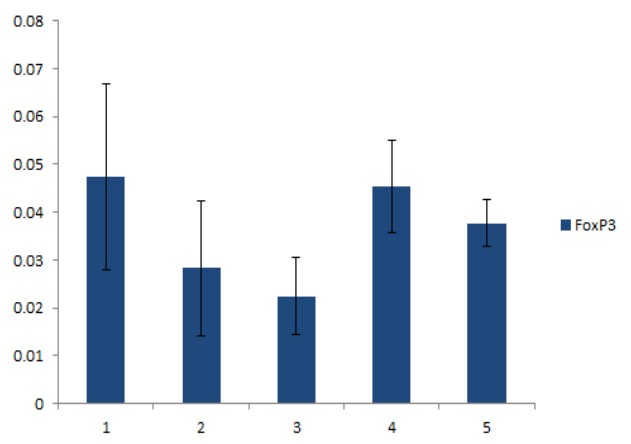

Figure 2. The mean of foxp3 protein expression of Lung issue in asthmatic rats

\section{DISCUSSION}

Pathogenesis of asthma has not been fully elucidated. With deeply researching for allergic diseases, the effect of Treg in asthma gradually attracted people's attention and become a hot topic. Foxp3 is the characteristic molecular of Tregs, it play a key role among Treg differentiation, development and maintenance of suppression [7-9]. There is closely relation between Treg and the severity and control of asthma symptoms [10].The research shows that MAPK family is closely associated with stress-mediated lung injury led to inflammation and oxidative. Especially inflammatory response, apoptosis of various diseases is mediated by p38MAPK. Blocking the signal transduction pathway may inhibit production of inflammatory cytokines in a certain extent and reduce oxidative stress damage [1]. Clinical studies also suggest that p38NAPK can plays an important regulatory role in adjusting the balance of oxidation and antioxidant [11], and lung tissue can increase some expression of inflammatory cytokines, reduceantioxidants such as SOD and GSH, and so on[12].

Based on TCM pathogenesis, asthma is related to disorders in water metabolism, involving multiple organs (lungs, spleen, and kidneys). Phlegmisa pathologic product causes asthma. Because phlegm stays in the lungs, the exogenous diet, emotional state, and weariness causes asthma because phlegm blocks the airway and increases lung-qi. Clinical treatment focuses on staging and diffident syndromes. CMD consists of Zhimahuang(Ephedra; 4 g), Huangqin (Scutelleria; 9 g), Cangerzi (Xanthium; 9 g), Tianzhuzi (Nandina domestica; 9 g), Lameihua (Chimonanthus praecox flowers; 9 g), and Hutuiziye (Elaeagnus leaf; 9 g).The results showed: CMD can decrease P38MAPK protein expression and increase Foxp3 protein expression. Asthma can be treated with CMD, which may be due to its regulatory effect on P38MAPK and Foxp3 protein expression.

\section{ACKNOWLEDGMENT}

Supported by the Shanghai Natural Science Foundation (No. 14ZR441500) and the Shanghai TCM Special Funds Project of Health and Family Planning (No. 2014JP029A). 


\section{REFERENCES}

[1] Chen J, Nie SN, Ren Y, et al. P38MAPK inhibitor of paraquat to protection of acute lung injury in rats. Journal of Medical Postgraduates, 27(4):357-360, 2014.

[2] Huang CP, Zhang ZX, Xun YJ. P38 lightning silk crack original activated protein kinase signaling pathways and bronchial airway inflammation. Section of Respiratory System Foreign Medical Sciences, 25( 9):656, 2005

[3] Wang YQ, Li FF, Teng ZZ. Characteristics of bronchial asthmatic rat airway reconstruction research. Chinese Journal of Tuberculosis and Respiratory Diseases, 26(11):728-729, 2003.

[4] Wang YQ, Li FF, Yan HX, et al. Compound MaQin decoction on the immune function of children with asthma. Shanghai Journal of Traditional Chinese Medicine, 40(4):3738, 2006.

[5] Zhongzhao Teng, Yiqin Wang, Fufeng LI, et al. Tracheal compliance and limit flow rate changes in a murine model of asthma [J]. Science in China Series C,51(10):922-931, 2008

[6] Ji NF, Bian T, Chen L.The establishment of the rat model with bronchial asthma and airway reactivity determination.
Acta Universitatis Medicinalis Nanjing(Natural Science),26(11):1018-1020, 2006.

[7] Wan YY, Flavell RA. Regulatory $\mathrm{T}$ cell functions are subvertedand converted owing to attenuated Foxp3 expression. Nature, 445: 766, 2007.

[8] Zheng Y, Rudensky AY. Foxp3 in control of the regulatory Tcell lineage. Nat Immunol, 8: 457, 2007.

[9] Zheng Y, Josefowicz SZ, Kas A, et a1. Genome-wide analysis ofFoxp3 target genes in developing and mature regulatory T cells. Nature, 445: 936, 2007.

[10] Shi YH, Shi ZZ, Wan HY, et al. Bronchial asthma patients with peripheral blood Th17, CD4 + CD25 + Treg cells express characteristics. Chinese Journal of Immunology, 26(8): 740-743, 2010.

[11] Lu Q1, Rau TF, Harris V, et a1. Increased p38 mitogenactivated protein kinase signaling is involved in the oxidative stress associated with oxygen and glucose deprivation in neonatal hippocampal slicecultures. Eur J Neurosci,34(7):1093-1101,2011

[12] Ii Zl, $\mathrm{Li} \mathrm{J,} \mathrm{Bu} \mathrm{X,} \mathrm{et} \mathrm{a1.} \mathrm{Age-induced} \mathrm{augmentation} \mathrm{of}$ p38MAPK phosphorylation in mouse lung. Exp Gerontol, 46(8):694-702, 2011. 